\title{
Caleidoscópio narrativo: uma experiência etnográfica no campo da desinstitucionalização psiquiátrica no sul do Brasil
}

Caleidoscópio narrativo: uma experiência etnográfica no campo da desintitucionalização psiquiátrica no sul do Brasil

Thomas Josue da Silva e Denise Regina Quaresma da Silva

\section{(2) OpenEdition Journals}

\section{Edição electrónica}

URL: https://journals.openedition.org/aa/2411

DOI: 10.4000/aa.2411

ISSN: 2357-738X

\section{Editora}

Programa de Pós-Graduação em Antropologia Social (UnB)

\section{Edição impressa}

Data de publição: 1 dezembro 2017

Paginação: 327-351

ISSN: 0102-4302

\section{Refêrencia eletrónica}

Thomas Josue da Silva e Denise Regina Quaresma da Silva, «Caleidoscópio narrativo: uma experiência etnográfica no campo da desinstitucionalização psiquiátrica no sul do Brasil», Anuário Antropológico [Online], v.42 n.2 | 2017, posto online no dia 12 junho 2018, consultado o 18 maio 2021. URL: http://journals.openedition.org/aa/2411 ; DOI: https://doi.org/10.4000/aa.2411

\section{@(@) $\Theta \Theta$}

Anuário Antropológico is licensed under a Creative Commons Atribuição-Uso Não-Comercial-Proibição de realização de Obras Derivadas 4.0 International. 


\title{
Caleidoscópio narrativo: uma experiência etnográfica no campo da desinstitucionalizaçáo psiquiátrica no sul do Brasil
}

\author{
Thomas Josue da Silva \\ UNIPAMPA \\ Denise Regina Quaresma da Silva \\ Universidade FEEVALE/Universidade La Salle
}

O campo da atenção psicossocial foi marcado historicamente pela presença monolítica da instituição psiquiátrica no começo do século XIX, com o surgimento das práticas de internamento e potentes aparatos manicomiais. Naquele momento, a medicina higienista passava a deter o conhecimento da loucura, emitindo enunciados sobre a doença mental. Antes do século XVIII, a loucura não era sistematicamente internada e era essencialmente considerada como uma forma de erro ou de ilusão; no começo da idade clássica, ela era vista como pertencendo às quimeras do mundo e podia-se viver no meio delas. A loucura só seria separada no caso de tomar formas extremas ou perigosas, sendo que os lugares reconhecidos como terapêuticos eram primeiramente a natureza, e as prescriçóes dadas pelo médico eram de preferência a viagem, o repouso, o passeio. Esquirol, ao fazer os planos de um hospital psiquiátrico, recomendava que cada cela fosse aberta para a vista de um jardim (Foucault, 2001).

A instituição psiquiátrica no Brasil foi constituída historicamente em seu modelo asilar como o lugar de confinamento e tratamento especialmente destinado aos loucos. Segundo Foucault (1990), instauraram a normalização e a regulação de práticas e saberes acerca da doença mental, que colocaram em marcha a consolidação da psiquiatria e, com isso, o processo de medicalização da loucura ou chamada doença mental. Para este autor, houve uma transfiguraçáo histórica da loucura em doença mental. Ele demonstra como a concepção de alienação mental de cunho psiquiátrico pode ser revista por uma arqueologia da loucura no Ocidente - do Renascimento à modernidade - como um fenômeno recente (Foucault, 2002). Assim, foi criado um espaço terapêutico específico, os asilos, para curar os agora denominados doentes, criando-se a alienação mental.

Nos anos 1960, no auge dos movimentos de contracultura, surgiu o Movimento da Antipsiquiatria, inicialmente na Inglaterra, liderada por psiquiatras e por intelectuais descontentes com o modelo manicomial de assistência e com os processos de desumanizaçáo impostos pelo poder psiquiátrico ao sujeito em 
sofrimento psíquico. Uma das questóes que os autores que compunham este movimento defendiam era uma crítica à concepção da doença mental como algo meramente nosológico. Eles recolocavam o debate da doença na esfera social e política, redimensionando a experiência do sofrimento psíquico numa interaçáo direta e mais ampla com a sociedade. No entanto, esse nunca foi um "Movimento", no sentido de unidade e grupo. Os autores foram denominados assim, mas não se viam como pertencentes a um movimento, pois cada pensador se embasava em correntes de pensamento distintas e defendia formas distintas de lidar com pacientes e definir a psiquiatria.

O primeiro a usar esse termo foi David Cooper, que fomentou o movimento antipsiquiátrico com Ronald Laing, Aaron Esterson, Thomas Szasz e Michel Foucault. Cooper (1977:37) afirmou: “a doença é uma tentativa desesperada para cada um se libertar de uma situação microssocial alienante, que descarrega sobre a vítima a alienação da realidade macrossocial. Nas condiçôes da sociedade burguesa esta tentativa de libertação é quase sempre abortada”. Para este autor, a doença psíquica era uma tentativa de se libertar das amarras alienantes da sociedade ou da família.

A antipsiquiatria busca desenvolver uma prática manicomial que respeite o ser humano. Como exemplo disso, citamos o Pavilhão 21, uma unidade experimental para jovens esquizofrênicos que Cooper dirigia na década de 1961 a 1965 no Shelly Hospital de Londres. No Pavilhão 21 reuniam-se doentes, enfermeiros e médicos em uma existência coletiva onde todo vestígio de hierarquização desaparecera, pois o doente, ao ficar circunscrito a normas rígidas da instituição que não faziam sentido algum para ele, esvaziava-se de sua dimensão humana.

$\mathrm{Na}$ perspectiva de Roudinesco et al. (1994:12), este movimento inaugurava uma visão mais política e sociológica sobre a experiência da loucura na sociedade. Segundo ela, este movimento propunha que, para esses rebeldes, a loucura não era uma doença, mas uma história: "a história de uma viagem, de uma passagem ou de uma situaçáo, das quais a esquizofrenia era a forma mais aperfeiçoada, porque traduzia em uma resposta delirante o desconforto de uma alienaçáo social e familiar”. Também Mannoni (1989) entende o mérito do movimento antipsiquiátrico como um marco histórico importante dentro do campo da psiquiatria moderna que pode permitir o resgate da voz da loucura fora do espaço demarcado da tradição institucional; o discurso psicótico é percebido no seio da sociedade, na vida cotidiana, como uma espécie de estilo de vida.

Da mesma forma, Foucault (1996:124), ao refletir sobre o Movimento da Antipsiquiatria, sustenta que a intenção dos antipsiquiatras era justamente questionar a ordem do poder médico, as estruturas do poder que embasavam 
tanto os discursos como as práticas acerca da doença mental e suas formas mais variadas de violência e de silenciamento do sujeito.

Este debate ganhou força e foi tomando corpo em diferentes partes da Europa. Podemos citar os trabalhos de Franco Basaglia (1985) na Itália, com sua obra magistral L'istituzione negata, em que o autor apresenta um relato, quase uma etnografia do cotidiano de um hospital psiquiátrico numa pequena cidade chamada Gorizia, que passava por um profundo processo de mudança institucional. Este processo de mudança foi impulsionado pela presença de críticas das formas de opressão e de violência resgatadas nos relatos dos atores no interior desta instituição. Lembra Basaglia (1985:9): “o tom polêmico e contestatório evidente nos testemunhos (de doentes, médicos, enfermeiros e colaboradores) não se deve ao acaso, já que nossa ação parte de uma realidade que só pode ser violentamente refutada: o manicômio".

Segundo Amarante e Giovanella (1994:141),

o aparato manicomial, é preciso insistir, não é o hospital psiquiátrico, embora seja a mais expressiva instituição na qual se exercita o isolamento: é o conjunto de gestos, olhares atitudes que fundam limites, intolerâncias e diferenças, em grande parte informadas pelo saber psiquiátrico, existentes de forma radicalizada no hospício, mas presentes também em outras modalidades assistenciais e no cotidiano das relações sociais.

Os ideais e as práticas reformistas contra as formas de opressão e de violência historicamente impostos pelo modelo manicomial de atençáo à saúde mental se convertem em preposiçóes anti-institucionalistas importantes na contemporaneidade. As chamadas Reformas Psiquiátricas, influenciadas em grande parte pelos movimentos antipsiquiátricos historicamente construídos (Basaglia, 1985; Cooper, 1977; Foucault, 2002), dão impulsos a novas formas de relaçáo do sofrimento mental na diversidade cultural e, consequentemente, à necessidade de ampliarmos as pesquisas sociais no campo da chamada desinstitucionalização psiquiátrica.

$\mathrm{Na}$ atualização do debate da desinstitucionalização, problematiza-se uma nova relação da alteridade entre sofrimento mental e sociedade. Trata-se de uma relação dialética que não pode ser reduzida ao fenômeno patológico de causa e efeito, dada a polissemia que a desinstitucionalização traduz sobre práticas e concepçóes do sofrimento mental e da sua relaçáo com o mundo social. O projeto da desinstitucionalização não está acabado, mesmo que tenhamos conquistado, em 2001, a Lei da Reforma Psiquiátrica 10.216. Os desafios para a afirmaçáo e efetiva ação acerca da desistitucionalização seguem em um contínuo e são enormes no nível político, assistencial e, sobretudo, cultural e social. Não basta acabar com 
as celas e os quartos do manicômio físico, como apontam Amarante e Giovanella (1994:141): “o aparato manicomial, é preciso insistir, não é o hospital psiquiátrico, embora seja a mais expressiva instituição na qual se exercita o isolamento: é o conjunto de gestos, olhares e atitudes que fundam limites, intolerâncias e diferenças, em grande parte informadas pelo saber psiquiátrico, existentes de forma radicalizada no hospício", presentes ainda "em outras modalidades assistenciais e no cotidiano das relaçôes sociais".

Neste sentido, compreendemos a desinstitucionalização não como um mero abandono físico do hospital psiquiátrico tradicional, ou uma reorganização administrativa de serviços de saúde mental, que Szasz (1974) chamou de "futilidade da Reforma Psiquiátrica", mas sobretudo como algo mais complexo e dinâmico, em constante movimento. Pensamos a saúde mental e a atenção psicossocial como campos que engendram complexidades, como processo - um processo que tem como base uma dimensão cultural e social para além de uma visão meramente clínica (Rotelli, 1990). Pois, como afirma Amarante (2007:63), “[...] um primeiro grande desafio é poder superar esta visão que reduz o processo à mera reestruturação de serviços, muito embora se torne evidente que os mesmos tenham de ser radicalmente transformados e os manicômios superados. Mas esta transformação não deve ser o objetivo em si, e sim consequência de princípios e estratégias que lhes são anteriores".

Nosso estudo propóe questionar as formas tradicionais de atenção ao fenômeno que o sofrimento mental evoca dentro da cultura biomédica, na direção de uma crítica reflexiva acerca da verticalização e hegemonia do modelo biomédico e psiquiátrico ainda vigentes no contexto da atençáo psicossocial contemporânea. Objetivamos analisar, desde uma perspectiva socioantropológica, a desinstitucionalização psiquiátrica e a medicalização da experiência do sofrimento mental, bem como as formas de tratamento em saúde mental, a partir da experiência em um atelier de arte vinculado a um serviço público de saúde mental no sul do Brasil. Para tanto, nos utilizamos do estudo etnográfico no campo da atenção psicossocial, preconizando as interfaces com a criação iconográfica, a saúde mental e as ciências humanas e sociais, na tentativa de contribuir para uma pesquisa social interdisciplinar acerca da atenção em saúde mental, em sintonia com os processos históricos e já consolidados da desinstitucionalização psiquiátrica (Basaglia, 1985; Laing, 1982; Rotelli, 1990).

Portanto, a discussão de uma etnografia em saúde mental embasada em narrativas tanto verbais como iconográficas (desenhos, pinturas, criaçóes visuais dos interlocutores) nos aproxima do debate socioantropológico sobre a complexidade da experiência com a doença mental. Além disso, resgata uma crítica potente 
aos modelos tradicionais de atenção em saúde mental, assim como oportuniza a expressão subjetiva da vivência do sujeito que sofre e de suas interpretaçóes de mundo, bem como as formas multifacetadas de lidar com o sofrimento mental no contexto sociocultural.

Nessa assertiva, o cenário da atenção psicossocial é habitado por novas perspectivas de enfrentamentos teórico-metodológicos e de produção de subjetividades marcadas pela diversidade cultural, obrigando-nos a relativizar e redimensionar o terreno árido da nosologia consagrada pelo poder psiquiátrico. Portanto, convida-nos a (re)pensar nossas posturas tanto do ponto de vista epistemológico como de reordenamento da visão da experiência com o sofrimento mental na sociedade contemporânea.

Desta forma, narrativas verbais e iconografias constituem uma etnografia no cenário psicossocial, revelando experiências humanas complexas com o sofrimento mental que não podem ser reduzidas por interpretaçóes clínicas ou meramente nosológicas. Sobretudo, evidenciam uma rica e diversa forma de comunicação e de expressão do sujeito que sofre e sua relação com o mundo social. Nosso estudo etnográfico, através da criação iconográfica em segmentos psicossociais, evidenciou a importância do estudo destas criaçóes como uma fonte rica de análise das representaçóes das experiências com o sofrimento mental.

Com isso, a relaçáo entre a criaçáo iconográfica - a imagem produzida - e o discurso verbal da pessoa em situaçáo de vulnerabilidade psíquica ajudou uma aproximaçáo qualitativa da experiência com o sofrimento mental. Além disso, possibilitou pensar em novas formas de fazer etnografia no campo psicossocial e adotar uma posição hermenêutica mais compreensiva acerca da complexidade que este fenômeno engendra na biografia destes sujeitos.

Ao lidar com criaçóes iconográficas no cenário psicossocial, estamos abordando formas de expressão criadoras que nos levam a relativizar o que entendemos pelo conceito burguês de arte hegemônica e institucionalizada (Bourdieu, 1996) em favor de um fazer artístico emic (desde dentro), à margem dos sistemas das artes oficial. Evidenciamos esta questão no processo de nossa interação no campo de estudo, onde presenciamos formas de entendimento e narrativas informantes acerca daquilo que eles concebiam e entendiam como arte, como observamos na fala deste interlocutor: "esta é minha arte, eu expresso aqui o que sinto... isto é minha arte”. Portanto, criaçóes iconográficas elaboradas por nossos interlocutores nos dão pistas de um fazer artístico contextual e próprio, a partir da escuta de narrativas verbais e da observação de criações visuais que nos brindam por uma riqueza de representaçóes acerca das vivências do sujeito com sofrimento psíquico e sua interface com o mundo. 


\section{Percurso metodológico}

Nosso objeto de pesquisa, por sua natureza complexa, foi constituído a partir de múltiplas narrativas, compostas por fragmentos de criaçóes iconográficas, narrativas verbais e contextos biográficos, tomando como empréstimo as ideias do mosaico metodológico de Becker (1999:104): "diferentes fragmentos contribuem diferentemente para nossa compreensão; alguns são úteis por sua cor, outros porque realçam os contornos de um objeto". Nossos fragmentos narrativos, sejam criaçóes iconográficas ou verbais, nos permitiram acessar as visóes de mundo que formaram parte importante de nosso itinerário etnográfico no contexto da atenção psicossocial, pois constituem relatos biográficos fundamentais para a perspectiva etnossociológica (Berteaux, 2005). Desta forma, privilegiamos, para este estudo qualitativo de cunho etnográfico, as investigaçóes acerca da experiência das narrativas do sofrimento mental e etnografia dentro da saúde mental e o recorte analítico de um estudo de caso (Good, 1994; Kleinman, 1988).

Integrou o desenvolvimento deste estudo o atendimento aos fundamentos éticos e científicos pertinentes, de acordo com a Resolução 510/2016, do Conselho Nacional de Saúde. Esta resolução preza pelo respeito às informaçôes que serão coletadas, preservando a confidencialidade dos dados obtidos e a dignidade dos sujeitos. Todos os participantes que consentiram voluntariamente em contribuir com este estudo assinaram o Termo de Consentimento Livre e Esclarecido (TCLE) e foram informados sobre o propósito da pesquisa e a intenção de salvaguardar o sigilo de suas identidades como uma premissa a ser respeitada prioritariamente pelo Código de Ética do Conselho Regional de Psicologia (CRP) e pela Declaração de Compromisso do Pesquisador. Além disso, foram assinados os termos de cedência dos direitos das imagens, autorizando a publicação das mesmas.

Nosso interlocutor será chamado de Pedro, nome fictício. Ele é frequentador do atelier e, através de suas criaçóes iconográficas e de seu discurso verbal, problematizamos algumas questóes importantes para o campo dos estudos qualitativos em saúde mental e para a desinstitucionalização psiquiátrica: discurso hegemônico acerca do tratamento da doença mental, modelos de atenção em saúde mental, institucionalização e desinstitucionalização de práticas de atendimento em saúde mental, subjetividade e experiência com o fenômeno do sofrimento psíquico.

Escolhemos Pedro para este estudo de caso porque, ao longo da interação com os demais frequentadores no Atelier de Expressão (ATE), observamos que seu processo de criação era muito distinto dos demais. Pedro expressava uma iconografia onde as composiçóes visuais eram associadas com o uso de palavras carregadas de significado, que ele próprio atribuía. Imagem e palavra não estavam desassociadas de suas composiçóes visuais, o que nos chamou a atenção em relação 
às demais produções. As criações visuais e narrativas de Pedro construíram um rico material etnográfico que analisamos neste estudo.

O ATE foi o cenário onde realizamos nosso estudo. Este local foi destinado ao desenvolvimento de atividades artísticas para usuários e usuárias da rede de serviços em saúde mental provenientes de centros públicos de atenção psicossocial a adultos, subsidiado pela Secretaria de Saúde da cidade de Novo Hamburgo (RS). Este centro de atenção psicossocial (CAPS II) preconizava um atendimento descentralizado, com ênfase no trabalho de inserção social e comunitário e de desenvolvimento integral destinado a pessoas em situação de vulnerabilidade psíquica e social, perfil este recomendado nas diretrizes da Lei da Reforma Psiquiátrica.

\section{Atelier de Expressáo:}

\section{um lugar de escuta e encontros com a criaçáo iconográfica}

Historicamente, o ATE foi um espaço público criado nos anos 1990 com o objetivo de sediar um programa social de desenvolvimento de atividades culturais a partir da linguagem das artes visuais destinado a pessoas assistidas pelo Serviço Municipal de Saúde Mental (SMSM), subordinado administrativamente à Secretaria de Saúde de Novo Hamburgo. Inicialmente, o ATE funcionava no ambulatório do SMSM, passando a funcionar no Atelier Municipal de Arte (AMA), que destinava salas para as atividades de expressão artística do ATE, bem como oficinas de artes visuais com a comunidade artística e com outros frequentadores da localidade. O funcionamento do ATE juntamente ao atelier municipal ocorria três vezes na semana, em grupos abertos, e a adesáo era voluntária.

A filosofia norteadora do trabalho no ATE seguia uma perspectiva de interação social com a comunidade artístico-cultural, visando a uma estratégia intersetorial fora do SMSM. O intuito era o desenvolvimento de uma atençâo integral e interdisciplinar por meio da produção artística, no que a Reforma Psiquiátrica brasileira defendia, a partir da II Conferência Nacional de Saúde Mental (1992), como "a busca de outros recursos de Atençáo Integral na comunidade fora do âmbito restrito do ambulatório de saúde mental, fomentando a integraçáo com outros profissionais de diversos campos do conhecimento, como por exemplo: trabalhadores das áreas de produção cultural, artes e educação" (CNSM, 1992:15).

O ATE náo era uma escola de arte nem tampouco um espaço de Deixar terapia, para indicar tratamento psicologicoterapia ou de oficinas de reabilitaçáo psicossocial. Este local configurou-se como um lugar de encontro (iconográfico) dos seus frequentadores com a comunidade artística da cidade, conforme diz um 
dos frequentadores: "aqui eu convivo com muita gente diferente, eu gosto muito, artistas, gente diferente lá do ambulatório de saúde mental... aqui eu pratico minha arte. Eu convivo com meus colegas, eu converso com eles".

Nesta direçáo, o trabalho realizado no ATE que apresentamos neste estudo antecipou historicamente uma série de discussóes acerca da busca de recursos comunitários não centrados exclusivamente no cenário assistencial tradicional dos serviços de saúde mental. Buscou integrar as pessoas com sofrimento psíquico, assistindo-as na comunidade e fugindo da perspectiva de criar oficinas terapêuticas isoladas nos serviços especializados de saúde mental, com um cunho normativo e disciplinador. No momento histórico de sua implantação, antes que a Lei da Reforma 10.216, de 2001, fosse sancionada no Brasil, é importante destacar a visita de Franco Rotelli a Novo Hamburgo na década de 1990. Rotelli é um psiquiatra, pesquisador e um dos atores mais importantes da Reforma Psiquiátrica Italiana que naquele momento integrava uma missão internacional através da Organização Mundial da Saúde (OMS) no país. Sua visita ocorreu porque ele buscava conhecer trabalhos relacionados à desinstitucionalizaçáo psiquiátrica na América Latina. Ao conhecer o trabalho do atelier, ele comentou: "aqui, neste lugar, junto com estas pessoas do ATE, vejo vida, vejo a criação de novas possibilidades de sociabilidade de relaçóes novas fora da doença”.

O ATE ocorria no ambulatório de saúde mental do SMSM. Com nossa inserção, migrou para outro espaço social mais amplo, para outras formas de sociabilidade, outras formas de relaçóes com a doença mental e o social. Essa discussão é atualizada nos estudos sobre a saúde mental e atenção psicossocial a partir do paradigma da desinstitucionalização psiquiátrica, conforme propóe por Amarante (2007), ao referir-se de forma crítica a práticas realizadas em oficinas ou ateliês de arte no interior dos serviços de saúde mental que não estabelecem relaçóes com o espaço sociocultural e comunitário mais amplo. Essas práticas são quase sempre vinculadas a uma noção meramente de ofício terapêutico, de adaptabilidade normativa. Este autor enfatiza a importância da criação de espaços de trocas sociais para os usuários de saúde mental fora do campo psiquiátrico.

O trabalho nas oficinas visava à promoção de novas formas de expressão subjetiva, ao resgate de singularizaçóes que são negligenciadas pela lógica da doença, do clínico. Fica evidente essa questão nas falas e nas representaçóes visuais dos frequentadores sobre o cotidiano, suas memórias, as questóes sociais e, sobretudo, as experiências subjetivas com a estigmatização do fenômeno saúdedoença mental. É como expresso na fala de uma das frequentadoras: "aqui, eu falo de mim, daquilo que eu sofro e sou discriminada, sabe? Desenho e pinto também... Diferente de lá do ambulatório de saúde mental, onde eu sou só tratada, 
só minha doença”. Outro frequentador expressa: “o atelier é uma inovação para o acompanhamento de cultura e de informação... No ambulatório é só doença, aqui eu expresso livremente minhas ideias e pensamentos”. As verbalizaçóes de nossos interlocutores neste novo espaço expressam o quanto eles se sentem distantes das marcas da doença e da normatividade clínica vivenciadas no ambulatório de saúde mental do município.

O ATE possibilitou um lugar de trocas sociais e de singularização, sem sombra de dúvida, o que nos aproxima das ideias de Rotelli (1990:91-92), ao refletir sobre a necessidade de romper com a lógica patologizante no campo da atenção psicossocial. Seria necessário criar, nestes cenários psicossociais, laboratórios de oportunidades onde o sujeito recuperasse sua singularidade e sua subjetividade "espaços de vida" e não de doença.

Pensando o atelier como um laboratório de oportunidades, nosso trabalho etnográfico nas oficinas de expressão artística nos oferece a percepção de um espaço não medicalizado, a partir de uma dialética social que figurou uma territorialidade habitada por expressôes iconográficas multiformes, por expressóes simbólicas, que revelaram cosmovisóes de mundo. Da mesma forma, esse era um lugar de convívio social distinto do ambulatório, onde as relaçóes eram pautadas por papéis fixos, numa relação de poder entre aqueles que tratam - os médicos e terapeutas - e aquele que é tratado: o usuário, marcado pela doença. Tal premissa fica evidente na fala desta usuária: "no ambulatório eu sou tratada, ninguém sabe de minha história de vida. Aqui, eu posso falar de minha vida, de minha história. Aqui eu desenho, eu pinto, eu converso com meus colegas".

Descontaminado do psicopatológico, o ATE se caracterizou como um espaço de interaçáo social que possibilitou uma escuta social distinta daquela escuta nosológica presente nos espaços tradicionais de atenção psicossocial. Assim, a criação iconográfica e o discurso verbal dos nossos interlocutores nos levaram a uma polissemia rica de representaçóes, que nos ajudou a construir um caminho etnográfico particular para refletir sobre a experiência do sofrimento psíquico e sua relação com o campo da atenção psicossocial. É o que vamos observar a seguir, na análise do estudo de caso de nosso interlocutor Pedro.

\section{Criaçóes iconográficas e saúde mental: possibilidades etnográficas no campo psicossocial}

A discussão sobre criaçôes iconográficas no campo psicossocial não é recente. Os estudos inaugurais do psiquiatra e historiador de arte Hans Prinzhorn, sobre iconografias produzidas por doentes mentais, reunidos nos princípios dos anos 1920 em sua coleção magistral na Universidade de Heidelberg, apontam para 
uma rica fonte de pesquisa do ponto de vista tanto da humanização do tratamento da doença mental como da qualidade artística observada nas produçóes estéticas oriundas desses contextos psiquiátricos (Prinzhorn \& Brockdorff, 1972).

Os movimentos da arte ocidental moderna também receberam uma forte influência de manifestaçóes estéticas oriundas de segmentos psiquiátricos, manifestações artísticas não institucionalizadas pelo circuito oficial da crítica de arte consagrada. Exemplo disso, nos meados dos anos 1940, o artista francês Jean Dubuffet, interessado por essas produçôes estéticas produzidas em segmentos psiquiátricos à margem dos sistemas artísticos dominantes, nomeou-as como arte bruta. Como Dubuffet (apud Chilvers, 1996:29) argumentava, "não há uma arte de loucos, assim como não há uma arte dos indivíduos dispépticos ou dos que possuem problemas de joelho”.

Já nos anos 1970, Roger Cardinal (1972) cunhou tais produçôes por outsider art. Todas estas tentativas de capturar ou definir tais eventos estéticos na esfera psiquiátrica não conseguem reduzir de forma unívoca ou disciplinar essa diversidade e densidade estética encontrada nas narrativas iconográficas de pessoas acometidas por sofrimento mental ou em situação de vulnerabilidade psíquica.

Todavia, nosso interesse não se limita em abordar o fenômeno da criação iconográfica no contexto psicossocial de forma a encontrar ressonância conceitual com uma filiação estética determinada. Nosso estudo privilegia uma produçáo iconográfica que se aproxima da produção de uma etnografia visual constituída no processo de criação visual dos próprios interlocutores, como fonte hermenêutica que vislumbra um contexto semântico no cenário psicossocial, na interface entre produção simbólica visual e experiência com a dimensão do sofrimento psíquico.

Não refutamos, sobretudo na observação de muitas das produções iconográficas que encontramos no campo em nossa trajetória etnográfica em saúde mental, um vigor e uma expressáo criadora ímpar. Tais produçóes originais poderiam ganhar notoriedade estilística e estética, como observamos a seguir na criação abstrata de uma das interlocutoras do ATE. Com as letras de seu nome, ela cria arranjos formais, gerando letrismos abstratos. Esta produção em particular poderia ser comparada com a criação de muitos artistas considerados como artistas brutos, segundo a perspectiva de Dubuffet (apud Chilvers,1996), pois mesclam figura e escrita em suas obras. 
Figura 1 Criação iconográfica de uma frequentadora do ATE

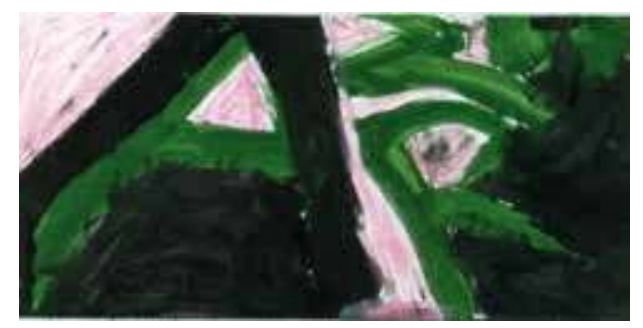

Contudo, seria uma utopia dizer que mesmo uma arte bruta, segundo sua histórica conceitualização, estaria livre das normas do campo artístico, como nos aponta Bourdieu (1996), em especial em sua análise sobre a arte bruta, onde afirma que os teóricos não podem constituir as produçóes artísticas dos esquizofrênicos em uma espécie de senso absoluto. Compartilhamos com a perspectiva deste autor, no sentido de que nossa referência náo foi buscar uma norma estilística, ou classificar as produçóes de nossos interlocutores do ATE em uma corrente da história da arte. Não podemos ignorar, retomando as reflexóes dele, que qualquer classificação segue um consenso hegemônico, uma doxa, uma crença compartilhada que vai estruturar um campo determinado e estabelecer relaçóes de poder.

Também Gorsen (1977), referindo-se ao estudo da arte e da psicopatologia, nos aponta para as questôes ideológicas que permeiam relaçóes de poder presentes na esfera da criação estética em segmentos psicossociais e institucionais clínicos. Alude que a atitude segregadora das clínicas psiquiátricas e dos seus arquivos começa a se dissolver em favor de uma pesquisa interdisciplinar e não apenas diagnóstica da expressão. As inferências deste autor nos ajudam a pensar nossa pesquisa neste campo, pois nos deparamos com manifestaçóes iconográficas e narrativas que possibilitam questionar formas ideológicas de classificação e segregação tanto no âmbito estético como no da atenção psicossocial. Por conseguinte, a pesquisa social nestes segmentos deverá contemplar novas abordagens teórico-metodológicas de base interdisciplinar para a compreensão deste fenômeno táo diverso e complexo.

A etnografia com imagens, parte importante de nossa investigação no contexto psicossocial, nos aponta para uma abordagem hermenêutica onde as imagens, carregadas de infinitas possibilidades semânticas, têm uma vida própria. Por isso, não podemos esgotar a análise iconográfica em interpretaçóes unidimensionais (Joly, 1994). Como as imagens visuais não podem ser decifradas em sua totalidade, para pensar o dispositivo iconográfico e lhe conferir sentido, deve-se considerar que uma imagem necessitará sempre, ainda que somente de forma provisória, 
de uma mediação verbal. Como esclarece Aumont (1993:248), “[...] a relação entre imagens e palavras, entre imagem e linguagem... não existe imagem pura, puramente icônica, já que para ser plenamente compreendida uma imagem precisa do domínio da linguagem verbal".

Quando utilizamos o dispositivo iconográfico para estudos qualitativos em ciências sociais, estamos buscando um recurso interpretativo que não seria possível somente com o uso de uma etnografia clássica constituída pelo texto escrito. Este tema é tratado por Goffman (1991:138-142) em uma importante contribuição teórica sobre seus estudos sobre representação social: "observemos, además, que el texto, que explica más o menos lo que pasa, suele ser, con frecuencia, algo superfulo, pues la imagen cuenta por si misma su própria historia”.

Nosso estudo centra-se em narrativas verbais e visuais que não vão buscar uma classificação artística nem psicopatológica da expressão, mas abrir possibilidades de encontros etnográficos no campo psicossocial - uma experiência local, mas substancialmente capaz de produzir uma amplitude do conhecimento acerca do "outro". Como nos aponta Geertz (1983, 2001), todo "saber local" é substantivo, é de alguém e, portanto, pode representar uma abertura significativa de conhecimento. Nessa assertiva, no estudo que apresentamos, o discurso de Pedro sobre sua obra é valorizado, na medida em que falava sobre ele sempre que desejava, dando-lhe sentido livremente a partir de seu mundo interno. Pedro, por vezes, retornava ao desenho dias depois de concluí-lo, conferindo-lhe sentido a partir de sua narrativa.

\section{Estudo de caso: imagens que falam do mundo iconográfico}

O desenho é a restauraçáo do paraíso... o desenho me faz bem... necessito desenhar. Uma viagem ao mundo desconhecido... que mundo desconhecido é este? Dentro de nossa limitação, não é possível conhecer (Pedro).

Apresentamos um breve relato de caso: a história de Pedro, que acompanhamos no trabalho de campo de nossa investigação etnográfica. Nas entrevistas, notas, desenhos, relatos e escritos de Pedro, encontramos alguns dados sobre sua biografia. Capturados inicialmente nos documentos do ambulatório de saúde mental do SMSM, estes dados informam que Pedro foi diagnosticado psiquiatricamente como esquizofrênico sem maiores especificaçóes (CID10.F20.9), com data de nascimento na cidade de Novo Hamburgo, situada no Vale dos Sinos, onde vive até hoje. Sua família é de classe média, constituída por cinco irmãos e a mãe, sendo que o pai é falecido. 
Sobre sua escolaridade, sabe-se que cursou até o sétimo ano primário. Nesta mesma época, sua família enfrentava uma crise econômica que obrigou Pedro a ingressar no mercado de trabalho aos 14 anos. Seu primeiro emprego formal foi numa empresa de metalurgia, onde permaneceu somente alguns meses. Após a saída deste trabalho formal, Pedro se inseriu na rede informal, sem vínculos laborais institucionais.

Segundo o que relata Pedro, após frustrante experiência com o mundo do trabalho, aos 16 anos, ele desejava seguir a carreira militar na Marinha Brasileira. Para tanto, esmerou-se muito a enviar carta de intençóes e documentos para seu alistamento. Seu sonho era participar do Programa Militar da Marinha Nacional. Seu esforço foi em vão. Logo, recebeu uma carta de contestaçáo por parte da Marinha Nacional, negando seu pedido de incorporação. Pedro comentou conosco na época: "eu desejava seguir a carreira militar da marinha, mas não consegui". Após este depoimento, Pedro desenhou a figura de um grande navio de combate e escreveu no verso da folha: "horizonte aberto. Mistério é o que vem antes do horizonte aberto... bonanza que existe depois da tempestade. Navio de combate".

Figura 2 Navio de combate

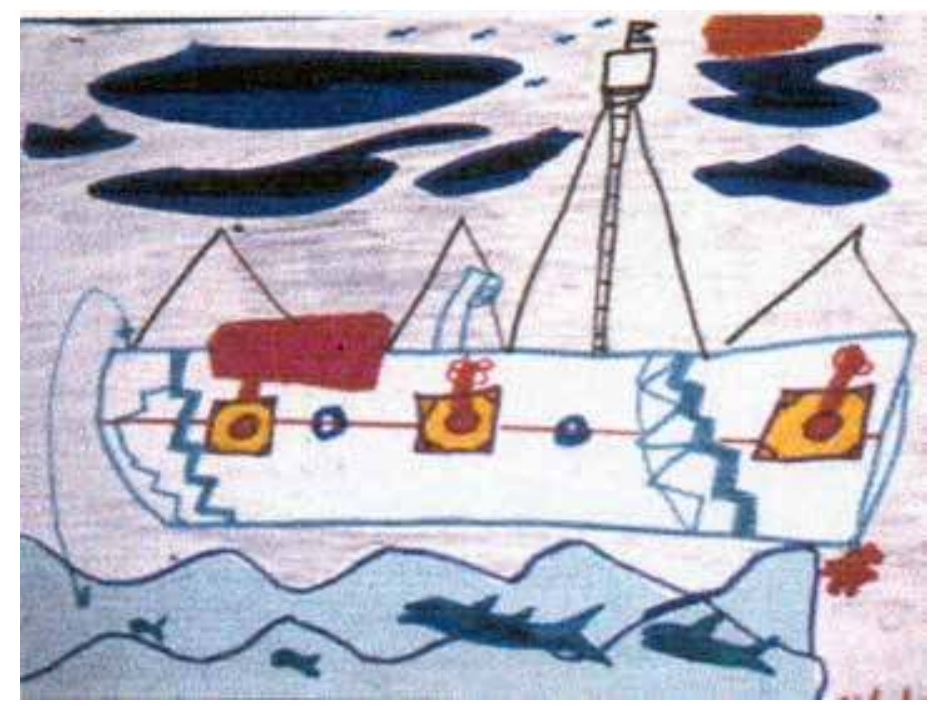

Aos 18 anos, Pedro teve seu primeiro surto, sendo encaminhado para a internação em um hospital psiquiátrico de outra cidade, onde permaneceu durante três meses. Ele relata que as atividades que mais lhe agradavam no hospital, durante sua internação, eram as realizadas nas oficinas de criação plástica. 
Nas primeiras interaçóes que tivemos com Pedro no atelier, narrativas da infância se mesclaram em criaçóes visuais e depoimentos verbais, como observamos neste fragmento de sua fala e na criação de uma iconografia que representa um parque infantil da cidade, onde brincava quando criança e para onde "ia" durante sua dolorosa internação no hospital psiquiátrico: "fugi da realidade... do local, e fugi para minha infância”. Ao desenhar e narrar esta passagem dolorosa, Pedro elabora esta dor, nomeando-a e compartilhando seu sofrimento, que acolhemos.

Figura 3 "Meu tempo de criança"

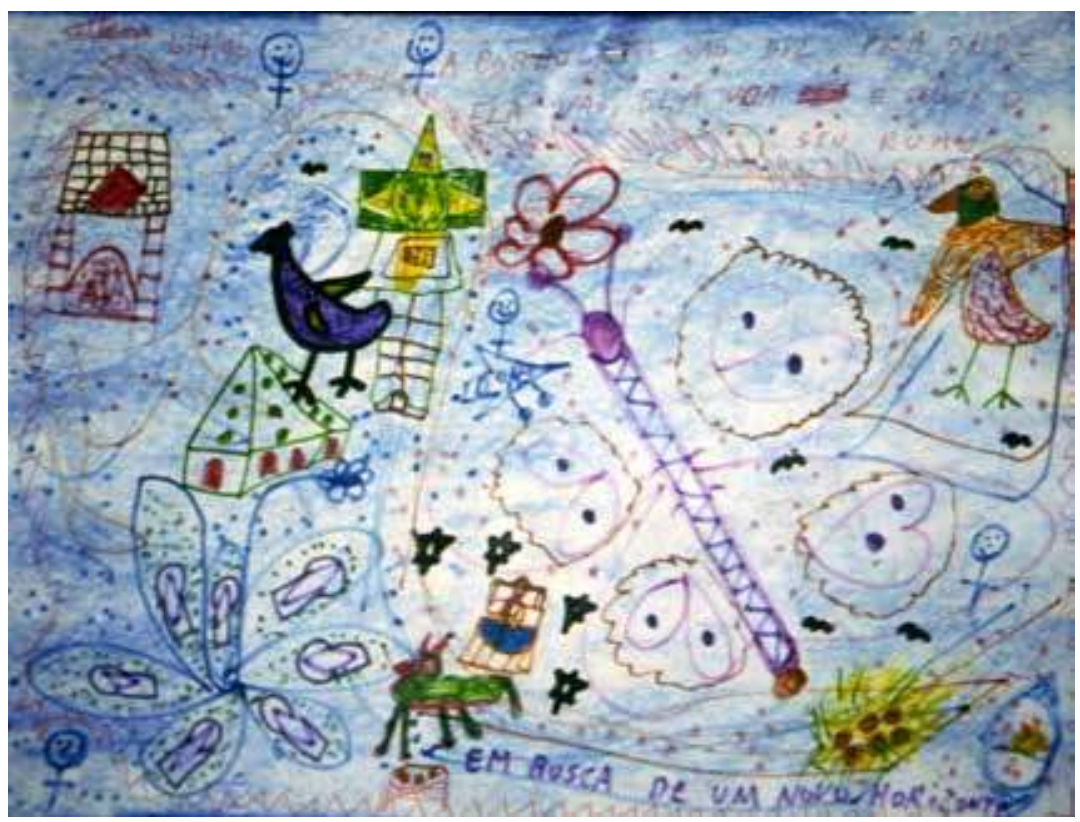

Nos anos que se passaram de nossa interação com Pedro no ATE, imagens e narrativas verbais figuravam uma sucessão de recordações de sua biografia infantil. Sobretudo nas iconografias associadas ao discurso verbal, observase a presentificação de um tempo biográfico que o interlocutor resgatava a cada momento de nossa interação com ele. Temas da memória infantil, bem como outros temas de suas experiências biográficas, ganhavam lugar nas suas expressóes visuais e narrativas verbais. Essas temáticas falavam de suas vivências em instituições psiquiátricas e de suas representaçôes acerca de temas de saúdedoença mental, como observamos na continuidade. 


\section{Vivências com as instituiçóes psiquiátricas e com a doença mental: criaçóes iconográficas e narrativas}

Observemos a imagem de uma cabeça desenhada ladeada por ondas circulares e com o acréscimo, na composição, de palavras ditas enquanto Pedro desenha. Estas se mesclam ao desenho e nos ajudam a perceber as ideias e as vivências de Pedro acerca do fenômeno do sofrimento psíquico: "um doente mental é um doente intelectual". E logo comenta: "só há um espaço quando a gente faz parte deste espaço”.

Figura 4 "O doente mental"

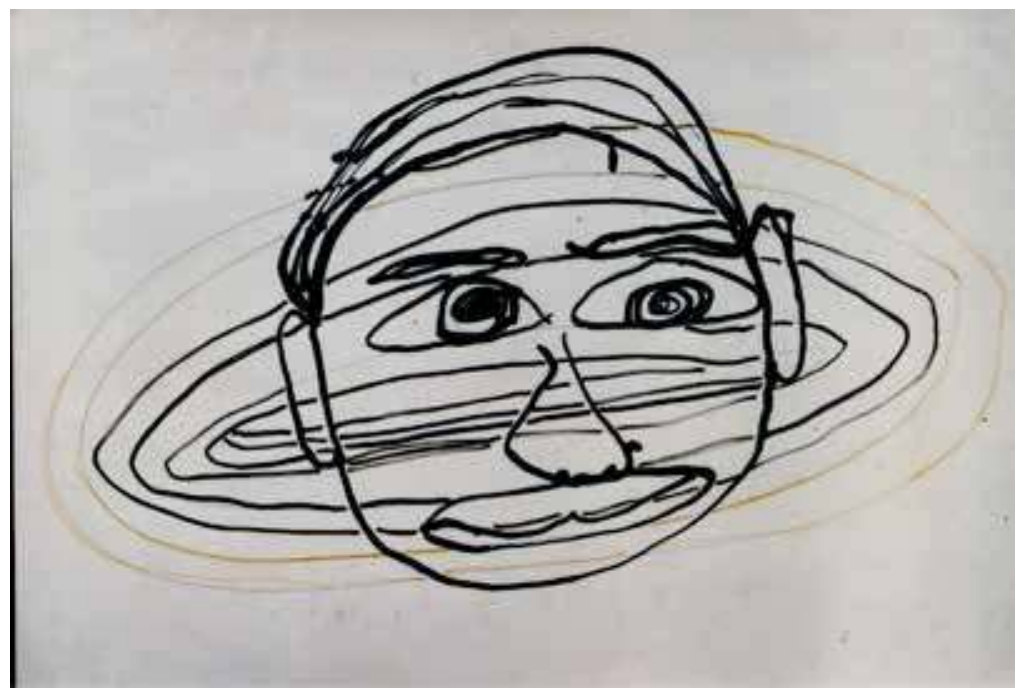

A representação de um "doente mental” e as palavras agregadas ao conjunto da composição formal de Pedro expressam indiscutivelmente a vivência do interlocutor com o fenômeno do sofrimento psíquico. Suas narrativas falam de suas vivências em instituiçôes psiquiátricas e de sua vivência com a própria dimensão do sofrimento psíquico, buscando representar sua experiência no campo do tratamento da doença. Neste segmento, ele desenha um consultório psiquiátrico e logo comenta: “o que é a esquizofrenia?” Pedro manifesta uma preocupação com a ontologia de sua doença. Assim, representa uma máe que vai dar à luz uma criança doente. Ele desenha esta figura feminina grávida, que ele diz "ser uma máe", e logo narra: "a doença... temos que prevenir antes que ele nasça”. 
Figura 5 "Origem da doença mental"

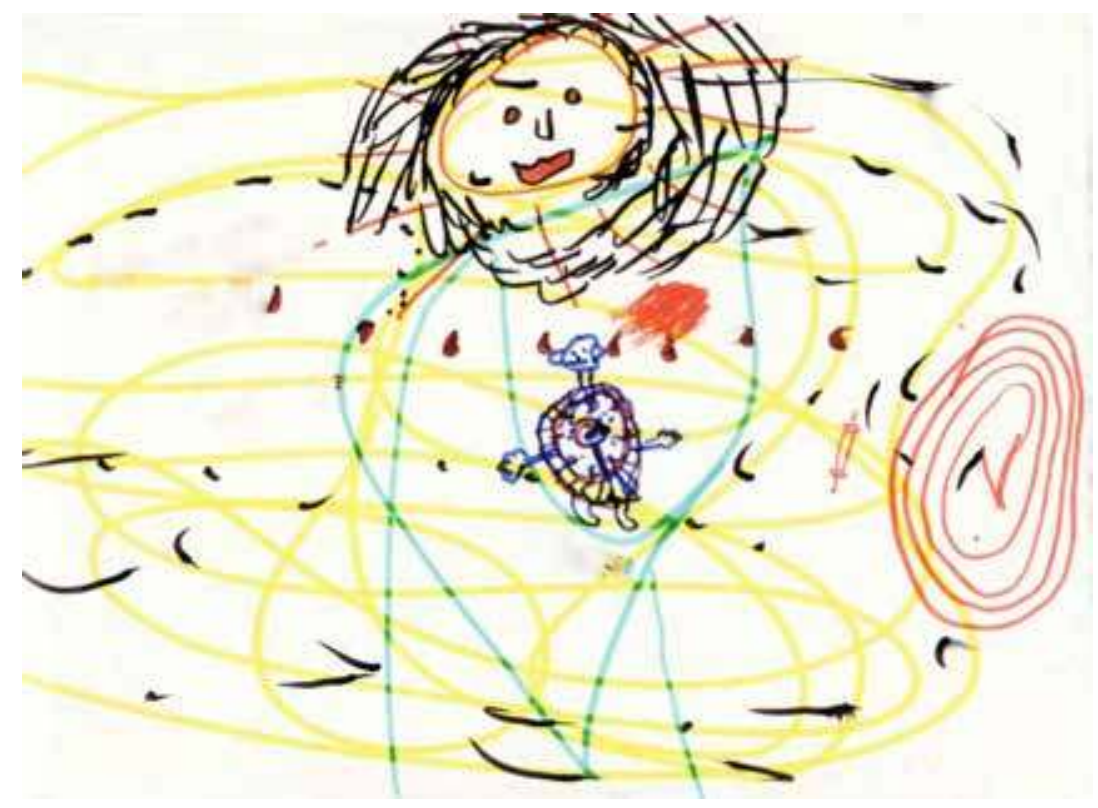

É importante ressaltar que suas narrativas verbal-iconográficas acerca da doença mental e do tratamento, como de sua ontologia, são recorrentes na sequência dos três anos que estivemos em contato com Pedro, sobretudo quando observamos sua ênfase nas lembranças dos territórios institucionais onde ele vivenciou suas primeiras internaçôes psiquiátricas. É como observamos neste relato do período: "eu tinha 18 anos... eu chorava muito... queria sair de lá... toda semana minha família me visitava. Eu tinha medo, ficava só lá, eu queria sair de lá”.

Ao mesmo tempo que observamos, nas narrativas visual-verbais de Pedro, relatos das experiências de internação vividas na instituição psiquiátrica, percebemos, na observação de campo, o presente de suas vivências e representaçóes no cenário da atenção psicossocial fora do âmbito hospitalar tradicional. É o que revela esta imagem criada pelo interlocutor, intitulada "Ontem e hoje": 
Figura 6 "Ontem e hoje"

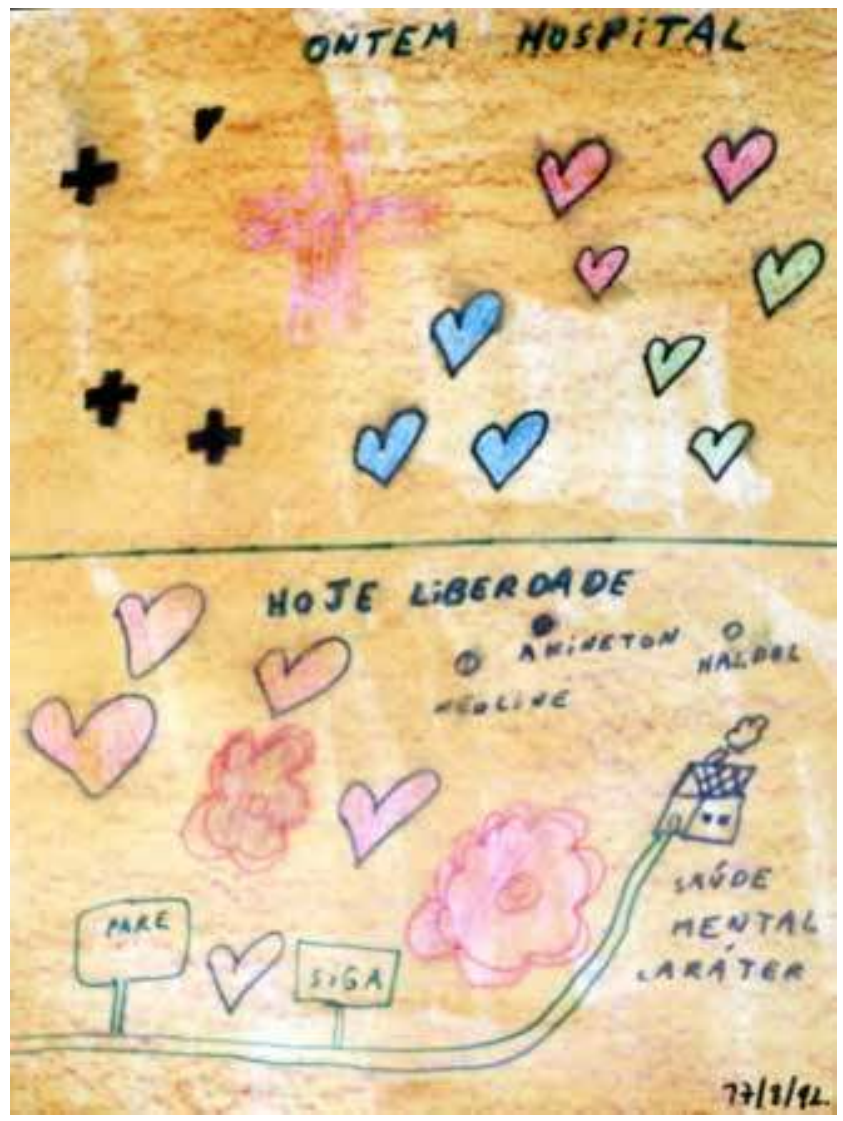

Esta criação iconográfica traduz uma narrativa visual-verbal importante do ponto de vista de nossa investigaçáo etnográfica, por evidenciar a capacidade de nosso interlocutor de comparar suas experiências psiquiátricas vividas no passado e aquelas que figuram as novas vivências com o tratamento psiquiátrico no contexto presente, distinto do aspecto hospitalar do passado. Tal questáo se evidencia na criação de uma composição que representa, através de uma linha cronológica, uma espécie de fronteira: em cima da linha, as experiências passadas nas instituiçóes psiquiátricas e, na parte inferior do desenho, o momento presente, isto é, seu tratamento no Serviço de Saúde Mental de Novo Hamburgo e sua vivência no ATE, como observamos nas duas frases agregadas na composição: "ontem hospital... hoje liberdade". Contudo, também se observam os nomes de psicofármacos presentes na parte do desenho referente ao hoje, o que sugere o quanto a experiência do ontem, no hospital psiquiátrico, faz sombra no seu presente, tatuando sua existência adoecida. Nas interlocuçóes com Pedro e com 
os demais usuários da rede de serviços de saúde mental, ao longo dos mais de vinte anos que temos, resta claro o potencial estigmatizante que uma internaçáo hospitalar psiquiátrica tem sobre um ser humano.

$\mathrm{Na}$ mesma temática, observamos Pedro elaborando uma iconografia que representa um manicômio. Nesta criação visual, ele expressa o interior de um manicômio agregando frases que denotam as vivências e concepçóes do interlocutor sobre o contexto manicomial.

Figura 7 "O manicômio"

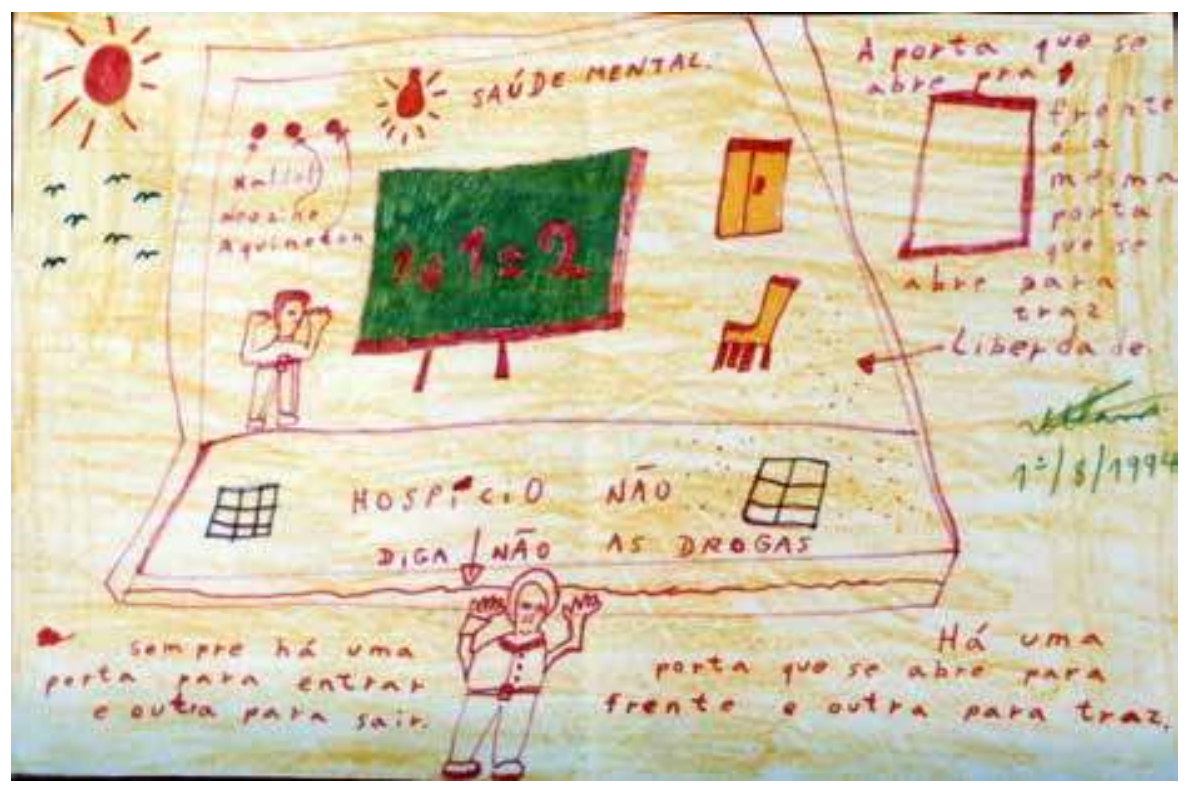

Após concluir o desenho intitulado "Manicômio", o interlocutor comenta: "eu já fui internado em um hospital psiquiátrico e chorava muito, desejava sair". Continua: "manicômio não é vida... as pessoas lá são abandonadas, ninguém quer saber delas lá... eu digo... hospício não". Pedro segue narrando: "os hospitais psiquiátricos são isolados. Existe o jardim e o edifício, que são o termo de acesso limitado. Janela com vidro e a moldura. A saúde mental é o convívio junto com a sociedade".

Observando a riqueza das criaçóes iconográficas e do discurso verbal de Pedro acerca da instituição psiquiátrica, do tratamento e da sua relaçáo com o sofrimento mental, podemos seguramente dizer que são construtos narrativos que traduzem fragmentos biográficos e formas que buscam dar significado e sentido a experiências com a dimensão do sofrimento psíquico, que nosso interlocutor 
expressa de forma muito particular. Em outras palavras, o repertório narrativovisual-verbal de Pedro dá sentido às experiências existenciais que marcaram sua biografia (Good, 1994).

Good contribui importantemente para o campo da antropologia médica, evidenciando as estratégias narrativas que o sujeito encontra para relatar e, ao mesmo tempo, dar significado e sentido ao que está vivenciando na dimensão doa seu sofrimento: "form in which experience is represented and recounted... in which activities and events are described along with the experiences associated with them and the significance that lends them their sense for the persons involved" (1994:139).

Considerando estas reflexóes, o estudo de caso de Pedro nos oferece um rico exemplo de estratégia narrativa no campo da atenção em saúde mental, onde imagens e discurso verbal se fundem num construto que expressa ideias e sentimentos sobre vivências com a doença mental e com a instituição psiquiátrica, transcendendo uma perspectiva unidimensional de escuta psicopatológica do fenômeno. Esta experiência etnográfica nos possibilitou uma abertura para uma escuta social e subjetiva do sujeito que sofre, bem como de suas estratégias narrativas para dar sentido e significado às experiências do sofrimento psíquico. Essas narrativas nos fazem compreender que as vivências com a doença-saúde mental náo se dão de forma fragmentada no sujeito, mas dentro de contextos e de relaçóes intersubjetivas com o entorno sociocultural, questáo bastante discutida pela tradição da antropologia médica nas últimas décadas (Hernáez, 2008; Kleinman, 1988).

Ao caracterizar o hospital psiquiátrico como instituição total, Goffman (1996) explica que esse caráter total age sobre o internado de maneira que o seu eu passa por transformaçóes dramáticas do ponto de vista pessoal e do seu papel social. Ele verificou este fato no hospital para doentes mentais e detalha o processo que o desencadeou descrevendo "o mundo do internado", que se inicia na chegada ao hospital, quando se sofre um processo de "mortificaçáo do eu" que suprime a "concepçáo de si mesmo" e a "cultura aparente" que traz consigo, que são formadas na vida familiar e civil e não são aceitas pela sociedade. De acordo com este autor, estes "ataques ao eu" decorrem do "despojamento" do seu papel na vida civil pela imposiçáo de barreiras no contato com o mundo externo, do "enquadramento" pela imposição das regras de conduta, do "despojamento de bens", que o faz perder seu conjunto de identidade e segurança pessoal, e da "exposição contaminadora" através da elaboração de um dossiê que viola a reserva de informaçáo sobre o seu eu "doente". Isso causa um "desequilíbrio do eu", retirando a autonomia e a liberdade do doente. Pedro denuncia este processo de 
mortificação: "manicômio não é vida... as pessoas lá são abandonadas, ninguém quer saber delas lá... eu digo... hospício não”.

Goffman (1996) aduz que decorre desses mecanismos de mortificação do eu a sensaçáo de fracasso do internado e um sentimento de que o tempo de internaçáo é perdido, mas precisa ser cumprido e esquecido, gerando uma angústia diante da ideia de retorno à sociedade e ao convívio social. Essa angústia advém de dois fatos: o internado se vê diante de uma nova posição social, que náo será a mesma quando sair do hospital, e do "desculturamento", ou seja, da impossibilidade de adquirir os hábitos atuais que a sociedade passará a exigir. Pedro escreve no desenho "O manicômio" (figura 7): "há uma porta que se abre para frente e outra que se abre para traz", falando de sua ambivalência perante as "portas" de seu viver: abrir ou fechar-se?

Estas imersōes e trocas possibilitaram inúmeras reflexões sobre a natureza subjetiva de cada indivíduo com seu entorno social, como esclarece Schütz (1993). A experiência com o sofrimento psíquico nos remete a pensar nas formas de dar significado a vivências extremas num processo dialético com o mundo social e real em que vivemos, em um contexto sociocultural em que estabelecemos relaçóes com o outro e onde, a partir do outro, nos constituímos.

\section{Consideraçóes finais}

Este trabalho de campo vislumbrou um caminho etnográfico trilhado na experiência com a criação iconográfica em saúde mental num contexto psicossocial que nos oportunizou o contato e a interação com universos subjetivos, biografias e representaçóes de mundo. O encontro com as criações iconográficas e as narrativas verbais de Pedro demonstrou, no percurso de nosso trabalho de campo, a necessidade de desenvolver pesquisas qualitativas no cenário da atençáo psicossocial que privilegiem uma postura dialógica em favor de uma escuta social mais contextual acerca da experiência do sujeito com sofrimento psíquico e de sua complexa interface com a rede de atendimento de saúde mental.

Percebemos, décadas depois de iniciado o movimento da Reforma Psiquiátrica, que ainda predomina um discurso hegemônico acerca do tratamento da doença mental, com uma leitura centrada somente no aspecto nosológico, desconsiderando as complexidades socioculturais e a subjetividade daquele que sofre. Percebemos que o próprio Pedro se refere também aos aspectos biomédicos, quando fala em "doença mental" ou quando escreve os nomes das medicaçóes, interpretando esses aspectos como referências a sua pessoa, pois os utiliza para falar de si mesmo. 
A Reforma Psiquiátrica no Brasil começa, de fato, com a Lei 10.216, de 2001. Antes, o que havia era a Luta Antimanicomial, que clamava pela reforma. Esta luta está em vigor ainda hoje, uma vez que a reforma é um processo em andamento, de ranços, avanços e retrocessos. Nesse sentido, postulamos que as elaboraçóes de Pedro nos possibilitaram apresentar os princípios e as preocupaçóes da reforma, inclusive essa condição de processo em andamento.

$\mathrm{O}$ atelier terapêutico constituiu um espaço facilitador de uma vivência nos moldes do proposto pela reforma, oferecendo um novo modelo de atençáo em saúde mental e desinstitucionalização do atendimento em doença mental, subjetividade e experiência com o fenômeno do sofrimento psíquico. No entanto, este serviço deixou de ser oferecido, na medida em que as políticas públicas priorizaram o enxugamento dos espaços de atendimento aos usuários dos serviços de saúde mental, contribuindo para a mercantilização da loucura nos serviços prestados pela rede privada de saúde (Vasconcelos, 2009). Esta problemática emergente revela a tensão entre a criação de políticas federais em saúde mental e sua implantaçáo nos municípios, uma vez que o funcionamento desses serviços concerne à realidade administrativa de cada município.

A respeito desse impasse, Luzio e Yasui (2010:23) referem que a institucionalização da Reforma Psiquiátrica transformou o Ministério da Saúde em seu principal ator e indutor chefe dos ritmos e dos rumos do processo. Porém, as experiências que não seguem os parâmetros estabelecidos nas portarias não têm mais espaço. Ironicamente, estes parâmetros têm como inspiração as experiências do CAPS (Centro de Atenção Psicossocial) e dos Naps (Núcleos de Assistência Psicossocial), marcadas pela invenção e criação, que se construíram e foram reconhecidas antes dessas regulaçóes atualmente em vigor.

Há um avanço do modelo empresarial capitalista na nossa sociedade, de tal forma que se estabelece como natural que "as famílias, os indivíduos, os bairros, as instituições públicas, ainda que educacionais ou de saúde, devem ser geridas como uma empresa" (Souza \& Cunha, 2013:657).

A desinstitucionalização psiquiátrica conduz a uma reflexão permanente dos dispositivos ideológicos e axiológicos das formas de cuidado e de desmedicalização do sofrimento mental, fator presente nos relatos biográficos e nas representaçóes iconográficas de nosso interlocutor.

Deste modo, quando endereçamos a Pedro uma escuta qualificada, dando-lhe voz e observando suas criaçóes iconográficas, entendemos que, por mais que tenha sido localizada em lugar demarcado, esta experiência é importante (Geertz, 1983, 2001) por nos possibilitar pensar que a desinstitucionalização é possível, não sendo apenas de ordem administrativa ou um rearranjo institucional (Szasz, 1974). 
Apontamos para a necessidade de pesquisas etnográficas que promovam abordagens interdisciplinares capazes de levar em consideração as dimensões intersubjetivas daqueles que vivem a experiência da enfermidade mental, considerando a relação com os contextos institucionais de assistência e cuidado e com os microcosmos socioculturais dos sujeitos, como evidenciamos nos relatos e nas criações iconográficas de Pedro. Estes estudos podem nos ajudar na constituição de uma reflexão crítica sobre os processos de medicalização e institucionalização da doença mental em nossa sociedade atual. É preciso que haja outras abordagens teóricas, não filiadas necessariamente ao campo "psi", que possibilitarão uma renovação do debate sobre a atenção psicossocial no meio acadêmico e nas formas de cuidado dos sujeitos em situação de vulnerabilidade psíquica, contra a excessiva medicalizaçáo da experiência da doença mental em nosso contexto contemporâneo.

Assim, ao retomarmos nosso contexto da pesquisa, nos deparamos com uma postura interacionista dialógica, constatando uma riqueza narrativa composta por imagens e biografias, que nos levaram a tensionar as formas tradicionais e históricas de tratamento psiquiátrico (Foucault, 1990). Esta forma atua como um caleidoscópio que nos convida a uma experiência imaginativa constante, que nunca cessa de nos oferecer novos arranjos formais, sempre em movimento. Assim, a experiência do sofrimento mental nos convoca a uma visão integradora e promotora da inclusáo social, onde a voz do interlocutor tem escuta, considerando sua subjetividade e seu contexto sociocultural.

Recebido em 29/09/2015

Aprovado em 23/01/2018

Thomas Josué Silva é doutor em antropologia pela Universidad de Barcelona, mestre em artes visuais pela Universidade Federal do Rio Grande do Sul e professor adjunto da Universidade Federal do Pampa. Contato: thomasjosuesilva@gmail.com.

Denise Regina Quaresma da Silva é psicóloga, doutora em educação, professora e pesquisadora da Universidade Feevale e da Universidade La Salle. Contato: denisequaresmadasilva@gmail.com. 


\section{Referências}

AMARANTE, Paulo. 2007. Saúde mental e atenção psicossocial. Rio de Janeiro: Fiocruz. AMARANTE, Paulo; GIOVANELLA, Ligia. 1994. O enfoque estratégico do planejamento em saúde mental. In: Paulo Amarante (org.). Psiquiatria social e reforma psiquiátrica. Rio de Janeiro: Fiocruz. p. 113-48.

AUMONT, Jacques. 1993. A imagem. Campinas: Papirus.

BASAGLIA, Franco. 1985. A instituição negada. Rio de Janeiro: Graal.

BECKER, Howard S. 1999. Métodos de pesquisa em ciências sociais. 4. ed. São Paulo: Hucitec.

BERTEAUX, Daniel. 2005. Los relatos de vida: perspectiva etnosociológica. Barcelona: Bellaterra.

BOURDIEU, Pierre. 1996. As regras da arte. São Paulo: Cia. das Letras.

CARDINAL, Roger. 1972. Outsider art. London: Praeger.

CHILVERS, Ian. 1996. Dicionário Oxford de arte. São Paulo: Martins Fontes.

CNSM. 1992. II Conferência Nacional de Saúde Mental: Cadernos do Ministério da Saúde do Brasil. Disponível em: http://bvsms.saude.gov.br/bvs/publicacoes/0208IIcnsmr.pdf. Acesso em: 16/1/2017.

COOPER, David. 1977. Qui sont les dissidents. Paris: Galilée.

FOUCAULT, Michel. 1990. La vida de los hombres infames. Madrid: Pipeta.

. 1996. A ordem do discurso. São Paulo: Loyola.

. 2001. "A casa dos loucos". In: . Microfísica do poder. Rio de Janeiro:

Graal. pp. 113-128

. 2002. História da loucura na idade clássica. Sáo Paulo: Perspectiva.

GEERTZ, Clifford. 1983. Local knowledge: further essays in interpretive anthropology. New York: Basic Books. 2001. Nova luz sobre a antropologia. Rio de Janeiro: Jorge Zahar.

GOFFMAN, Erving. 1991. Los momentos y sus hombres. Textos seleccionados y presentados por Yves Winkin. Barcelona: Paidós.

.1996. Manicômios, prisões e conventos. SãoPaulo, Perspectiva. 
GOOD, Byron. 1994. Medicine, rationality and experience: an anthropological perspective. Cambridge: Cambridge University Press.

GORSEN, G. 1997. “Arte, literatura e psicopatología hoje”. In: H. G. Gadamer \& P. Vogler. Nova antropologia: o homem em sua existência biológica, social e cultural. São Paulo: Edusp. p. 264-294.

HERNÁEZ, Ángel M. 2008. Antropología médica: teorías sobre la cultura, el poder y la enfermedad. Barcelona: Anthropos.

JOLY, Martine. 1994. Introducción a l'analyse de l'image. Paris: Nathan.

KLEINMAN, Arthur. 1998. The illness narratives. New York: Basic Books.

LAING, Ronald D. 1982. Sobre loucos e sãos. São Paulo: Brasiliense.

LUZIO, Cristina A. \& YASUI, Silvio. 2010. "Além das portarias: desafios da política de saúde mental”. Psicologia em Estudo, v. 15, n. 1, p. 17-26.

MANNONI, Maud. 1989. Da paixão do ser à "loucura" de saber. Trad. Vera Ribeiro. Rio de Janeiro: Zahar.

PRINZHORN, Hans \& von BROCKDORFF, Eric. 1972. Artistry of the mentally ill. New York: Springer.

ROUDINESCO, Elisabeth et al. 1994. Foucault: leituras da história da loucura. Trad. Maria Igoes Duque Estrada. Rio de Janeiro: Relume-Dumará.

ROTELLI, Franco. 1990. A desinstitucionalização. São Paulo: Hucitec, 1990.

SCHÜTZ, Alfred. 1993. La construcción significativa del mundo social. Barcelona: Paidós.

SOUZA, Tadeu de P. \& CUNHA, Gustavo T. 2013. "A gestão por meio da avaliação individualizante e competitiva como elemento comum nas políticas públicas e gerenciais contemporâneas: uma contribuição crítica a partir de Michel Foucault". Saúde em Debate, v. 37, n. 99, p. 655-663.

SZASZ, Thomas. 1974. O mito da doença mental. São Paulo: Zahar.

VASCONCELOS, Eduardo Mourão. Saúde mental e serviço social: o desafio da subjetividade e da interdisciplinaridade. 4 ed. São Paulo, Cortez, 2009. 


\section{Resumo}

Este artigo aborda uma experiência etnográfica no campo da atenção psicossocial no contexto da desinstitucionalização psiquiátrica e se desenvolveu por meio de uma etnografia constituída pelo dispositivo iconográfico (pinturas, desenhos e criaçôes deimagens) de usuários desaúde mental de um atelier de arte ligado a um serviço público de saúde mental no sul do Brasil. Objetivamos analisar, desde uma perspectiva socioantropológica, a desinstitucionalizaçáo psiquiátrica, a medicalização da experiência do sofrimento mental, bem como as formas de tratamento em saúde mental. Metodologicamente, trata-se de um estudo qualitativo de cunho etnográfico com o recorte analítico de um estudo de caso e embasamento teórico nos estudos acerca da experiência das narrativas do sofrimento mental (Good, 1994; Kleinman, 1988). Concluímos que, mesmo com o movimento da Reforma Psiquiátrica, ainda predominam discursos e práticas centradas nos aspectos nosológicos no campo da saúde mental, desconsiderando as complexidades socioculturais e a intersubjetividade do indivíduo que sofre. Urge tensionar as formas tradicionais que a cultura biomédica evoca sobre o sofrimento mental em nossa sociedade contemporânea.

\section{Palavras-chave:}

Desinstitucionalização psiquiátrica, sofrimento mental, exclusão social, estudo etnográfico, saúde mental.

\section{Abstract}

This article addresses an ethnographic experience of psychosocial care in the context of psychiatric deinstitutionalization. It was developed through an ethnography constituted by iconographic expressions (paintings, drawings and images) of mental health clientsinatherapeuticstudio in the south of Brazil. Our goal is to analyze, from a socio-anthropological perspective, the psychiatric deinstitutionalization, the medicalization of the experience of mental suffering, as well as the forms of treatment in mental health. Methodologically, it is a qualitative ethnographic case study, based on the experience of the narratives of mental suffering (Good, 1994; Kleinman, 1988). We conclude that, despite the psychiatric reform movement, there is still the predominance of speeches and practices focused on nosological aspects in the area of mental health, disregarding the sociocultural complexities and the intersubjectivity of the individual who suffers. It is urgent to consider the traditional forms that biomedical culture evokes about mental suffering in our contemporary society.

Keywords: Psychiatric deinstitutionalization, mental suffering, social exclusion, ethnographic study, mental health. 